COMUNICAÇÃO CIENTÍFICA

\title{
CARACTERIZAÇÃo MORFOLÓGICA DA SEMENTE E DA PLÂNTULA DE BACURIZINHO (Rheedia acuminata (Ruiz et Pav.) Plachon et Triana - CLUSIACEAE) ${ }^{1}$
}

\author{
WALNICE MARIA OLIVEIRA DO NASCIMENTO², JOSÉ EDMAR URANO DE CARVALHO², \\ CARLOS HANS MÜLLER ${ }^{2}$
}

\begin{abstract}
RESUMO - O bacurizinho é uma espécie frutífera do gênero Rheedia, nativa da Amazônia, e raramente cultivada, pois seus frutos, embora comestíveis, apresentam polpa escassa. Os estudos com o bacurizinho visam a sua utilização como porta-enxerto, redutor de porte para outras espécies do gênero Rheedia e Garcinia que apresentam altura elevada, como o bacuripari (Rheedia macrophylla Planchon et Triana- Clusiaceae) e o mangostão (Garcinia mangostana L.). Este trabalho teve como objetivo caracterizar, morfologicamente, a semente e a plântula dessa espécie. A semente é exalbuminosa, bitegumentada, com a testa de coloração marrom, apresentando vários feixes vasculares bem visíveis, distinguindo-se por sua coloração um pouco mais clara. O hilo é arredondado, de coloração escura, com pequena região mais clara ao centro, correspondendo no ponto de entrada de feixe vascular. A micrópila situa-se próxima ao hilo, sobre uma pequena protuberância triangular. O embrião é anômalo, hipocotilar e é representado unicamente por um longo eixo hipocótiloradícula, sendo os cotilédones diminutos, aparecendo apenas na extremidade superior no lado oposto da micrópila. Durante a germinação, ocorre primeiramente a emergência de delgada raiz primária, no pólo oposto onde será originado o epicótilo. Essa raiz cresce aproximadamente $5-7 \mathrm{~cm}$ e cessa, fenecendo posteriormente. Por ocasião da emergência do epicótilo, ocorre ao mesmo tempo a formação de uma raiz adventícia, na base do epicótilo, bem mais robusta que a anterior e que se constituirá no sistema radicular da planta. Precedendo a abertura do primeiro par de metáfilos, desenvolvem-se no epicótilo três pares de catafilos opostos e de coloração esverdeada. A germinação é hipógea e a plântula do tipo criptocotiledonar.
\end{abstract}

Termos para indexação: fruto da Amazônia, hipogeal, criptocotiledonar.

\section{MORPHOLOGICAL CHARACTERIZATION OF SEEDS AND SEEDLINGS to Rheedia acuminata.}

ABSTRACT- The Rheedia acuminata is a fruit tree species native of the Amazonian, rarely cultivated, since your fruits, although comestibles, presents scarce pulp. The studies with the Rheedia acuminata seek the use as rootstock, reducing the size for other species of the genus Rheedia and Garcinia that present high height, as the Rheedia macrophylla and the mangosteen (Garcinia mangostana L.). This work had as objective characterize morphologically the seed and the seedling of this specie. The mature seed are anatropous, becoming bitegmic and exalbuminous. The tegument shows vascular bundle and a dark-brown coloration. The hilum is rounded, with dark coloration and small clearer area in the center, corresponding to the point of entrance of vascular bundles. The micropyle locates near to the hilum, on a small triangulate protuberance. The embryo is anomalous, hypocotylar and it is only represented by the long radicle-hypocotyl axis, being just the tiny cotyleadons, showing in the superior extremity on the opposite side of the micropyle. During the germination, happens the emergency of thin primary root firstly, in the opposite pole from where will arise the epicotyl. That root increases $5-7 \mathrm{~cm}$ approximately and it ceases, dying later. For occasion of the emergency of the epicotyl, happens the formation of a adventitius root at the same time, in the base of the epicotyl, more robust than the previous and that will be constituted in the radicular system of the plant. Preceding the first metaphylls pair's opening, are developing in the epicotyl equal, three of opposite cataphylls and of greenish coloration. The seedlings is cryptocotylar, with a hypogeal germination.

Index terms: Amazonian fruit, hypogeal, cryptocotylar.

A Rheedia acuminata (Ruiz et Pav.) Plachon et Triana - Clusiaceae, conhecida como bacurizinho (Pará), bacuri-deespinhos (Amazonas), limãozinho (Mato Grosso), pakoeli e swampoe-pakoeli (Suriname) é uma espécie frutífera de pequeno porte, nativa da Amazônia e raramente cultivada, pois seus frutos, embora comestíveis, apresentam escasso rendimento da parte comestível (Van den Berg, 1979; Cavalcante, 1991).
Os estudos com essa espécie visam a sua utilização como porta-enxerto ananicante para outras espécies frutíferas dos gêneros Rheedia e Garcinia, que apresentam porte elevado, como o bacuriparizeiro (Rheedia macrophylla Planchon et Triana) e o mangostãozeiro (Garcinia mangostana L.).

Dentro do táxon genérico Rheedia, existe certa dificuldade na distinção das espécies, sendo $R$. acuminata

1 (Trabalho 109/2001). Recebido: 25/05/2001. Aceito para publicação: 03/06/2002.

2 Eng ${ }^{\circ}$ Agr ${ }^{\underline{0}}$ M.Sc - Pesquisador da Embrapa Amazônia Oriental, Trav. Dr. Enéas Pinheiro s/n, Caixa Postal 48, CEP: 66017-970, Belém, PA walnice@cpatu.embrapa.br; urano@cpatu.embrapa.br; hans@cpatu.embrapa.br 
freqüentemente confundida com $R$. brasiliensis (Martius) Plachon et Triana, $R$. benthamiana Planchon et Triana e $R$. madruno Plachon et Triana, embora seja facilmente caracterizada por seus frutos rostrados, verrucosos e semi-equinados. No entanto, quando em início de formação, os frutos dessa espécie são muito semelhantes aos de $R$. benthamiana e, quando bem desenvolvidos, mostram semelhança com os de R. madruno (Van den Berg, 1979).

Estudos de morfologia de sementes e de frutos de Rheedia spp, desenvolvidos por Villagómez Rojas (1990), mostraram que as sementes dessas espécies possuem geralmente, forma elipsoidal, com coloração externa castanha e com linhas claras, longitudinalmente, bem visíveis, semelhantes a nervuras. Internamente, são de coloração branco-amarelada e todas as espécies exsudam látex amarelo.

Este trabalho teve como objetivo caracterizar morfologicamente a semente e a plântula de Rheedia acuminata, visando a subsidiar estudos futuros de taxonomia.

O estudo foi conduzido no Laboratório de Ecofisiologia e Propagação de Plantas da Embrapa Amazônia Oriental, em Belém-PA, no período de janeiro a março de 1999. Foram utilizadas sementes extraídas de frutos completamente maduros, caracterizados pela coloração amarela do epicarpo e pela consistência mole do endocarpo (Figura $1 \mathrm{~A}$ ), coletados de plantas estabelecidas no Campo Experimental da Embrapa Amazônia Oriental, em Belém-PA.

Biometria das sementes - para a mensuração das sementes, foram utilizadas 50 unidades de material fresco, determinando-se o comprimento e o diâmetro, com o auxílio de um paquímetro digital. Morfologia da semente - consideraram-se, na caracterização morfológica externa, os seguintes aspectos, conforme a recomendação descrita por Damião Filho (1993): coloração e formato, localização do hilo, da micrópila e do embrião.

Para o estudo das estruturas internas, foram efetuados cortes longitudinais e transversais nas sementes, verificando-se a presença e o tipo de tecido de reserva, o tipo de embrião e sua posição, forma, coloração e diferenciação do eixo embrionário. Anotaram-se, também, a forma e a posição relativa dos cotilédones e do eixo hipocótilo-radícula. As observações e as ilustrações das estruturas foram feitas em estereomicroscópio e microscópio ótico, ambos providos de câmara clara, acompanhada de escala milimétrica. A terminologia adotada para a descrição das sementes foi baseada no proposto por Corner (1976) e de Barroso et al. (1999).

Morfologia da plântula - para a caracterização morfológica da germinação e da plântula, as sementes foram semeadas em bandejas de plástico, com dimensões de $42 \mathrm{~cm}$ x $22 \mathrm{~cm} \times 5 \mathrm{~cm}$, contendo, como substrato, a mistura de areia e serragem, na proporção volumétrica de 1:1. Esse substrato foi previamente esterilizado em água fervente, durante duas horas, e umedecido com $70 \%$ de sua capacidade de retenção de umidade. A quantidade de água adicionada ao substrato, para obtenção daquele grau de umidade, foi calculada de acordo com a metodologia descrita pelas Regras de Análise de Sementes Brasil (1992). No total, foram semeadas 200 sementes, distribuídas proporcionalmente em quatro bandejas, as quais foram mantidas em condições de ambiente natural de Belém (temperatura média de $26,6^{\circ} \mathrm{C}$ e umidade relativa do ar de $87,5 \%$ ).

Após o início da germinação, que ocorreu aos dez dias após a semeadura, aproximadamente, foram retiradas, em intervalos regulares de cinco dias até aos 45 dias, plântulas representativas de cada fase da germinação e desenhadas com o auxílio de câmara clara, acoplada a um estereomicroscópio. A descrição da plântula foi efetuada segundo Duke (1965) e Oliveira (1993).

Biometria das sementes- as sementes de Rheedia acuminata apresentam formato elipsóide, com comprimento de $3,05( \pm 0,30) \mathrm{cm}$ e diâmetro de $2,75( \pm 0,29) \mathrm{cm}$, consoantes com os resultados encontrados por Villagómez Rojas (1990).

Morfologia da semente- as sementes de $R$. acuminata são anátropas, a exemplo de outras espécies do mesmo táxon genérico (Corner, 1976), exalbuminosas, bitegumentadas. A micrópila está localizada na base do hilo sobre uma pequena protuberância com formato triangular (Figura $1 \mathrm{~A}$ ). A testa é de cor marrom, apresentando várias cicatrizes bem visíveis, de coloração um pouco mais clara, como descrito por Villagómez Rojas (1990).

O embrião é hipocotilar, caracterizado pelo desenvolvimento acentuado do eixo hipocótilo-radícula, apresentando cotilédones rudimentares sob a forma de duas pequenas asas membranáceas, visualizadas apenas na extremidade superior do lado oposto à micrópila. A semente madura é desprovida de endosperma, estando todo o material de reserva armazenado no volumoso eixo hipocótilo-radícula, a exemplo do que ocorre nas sementes de outras espécies do mesmo gênero e também no gênero Platonia como foi observado por Mourão \& Beltrati (1995) em sementes maduras Platonia insignis. Esse tipo de tecido de reserva também é comum nas sementes de outras espécies da família Clusiaceae, dos táxons Clusia, Platonia, Symphonia, Tovomita e Tomitopsis (Barroso et al., 1999).

Morfologia da plântula - o processo germinativo das sementes dessa espécie inicia-se, sob condições ambientais referidas, aos dez dias após a semeadura, aproximadamente, com a emissão de uma delgada raiz primária no pólo oposto onde se originará o epicótilo (Figura 1 B). Essa raiz cresce cerca de $5-10 \mathrm{~cm}$ e, por ocasião da emergência do epicótilo, diminui acentuadamente sua taxa de crescimento (Figura $1 \mathrm{C}$ ). Quando ocorre a emergência do epicótilo, 10 a 15 dias após a semeadura, paralelamente, há a formação de uma raiz adventícia em sua base, bem mais vigorosa que a anterior, que se constituirá no sistema radicular definitivo da planta (Figura 1 D). À medida que a raiz adventícia se desenvolve, a outra fenece e, quando a plântula está em fase de nutrição exclusivamente autotrófica, já não faz mais parte de sua estrutura. Esse tipo de morfologia da germinação foi observado por Enoch (1980) em sementes de mangostão (Garcinia mangostana L.). Antes do aparecimento do primeiro par de metáfilos, que se verifica cerca de 45 dias após a semeadura, desenvolvem-se de dois a quatro pares de catáfilos opostos, de aspecto esverdeado (Figura $1 \mathrm{E}$ ), semelhante ao observado por Mourão \& Beltrati (1995) em plântulas de bacurizeiro (Platonia insignis Mart.).

A raiz é axial, podendo-se observar, quarenta e cinco dias após a semeadura, a presença de raízes laterais que se tornam bastante ramificadas (Figura $1 \mathrm{~F}$ ).

As características morfológicas das sementes de Rheedia acuminata são semelhantes às de outras sementes

Rev. Bras. Frutic., Jaboticabal - SP, v. 24, n. 2, p. 555-558, agosto 2002 


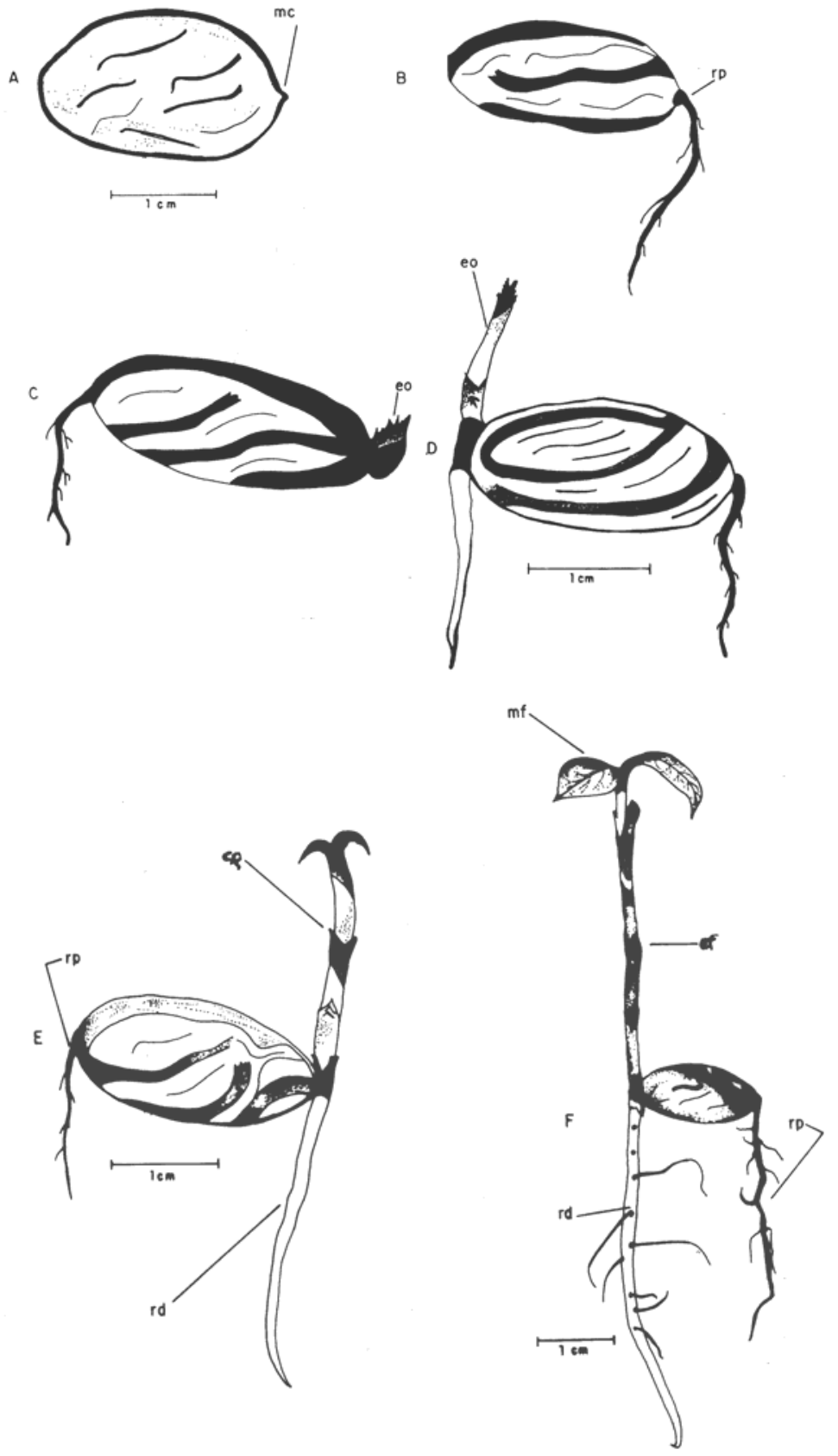

FIGURA 1 - Estádios sucessıvos de desenvolvımento da pläntula de $R$. acuminata. A. semente entumescıda, 5 dias após a semeadura; B- 10 dias após a semeadura; C- 15 dias após a semeadura; D- 15 dias após a semeadura; E- 30 dias após a semeadura; Fplântula completa 45 dias após a semeadura $(\mathbf{e o = e p i c o ́ t i l o ; ~} \mathbf{r p}=$ raiz primária; $\mathbf{c f}=$ catáfilo; $\mathbf{m f}=$ =metáfilo; $\mathbf{r d}=$ raiz adventícia; $\mathbf{m c}=$ micrópila).

dos gêneros Rheedia, Platonia e Garcinia, enquanto a morfologia da germinação e a plântula assemelha-se bastante com as das espécies Garcinia mangostana e Platonia insignis.

\section{REFERÊNCIAS BIBLIOGRÁFICAS}

BARROSO, M.G.; MORIM, M.P.; ICHASO, C.L.F. Frutos e se- mentes: morfologia aplicada à sistemática de dicotiledôneas. Viçosa: UFV, 1999. 443p.

BRASIL. Ministério da Agricultura e Reforma Agrária. Regras para análise de sementes. Brasília: SNDA/DNDV/CLAV, 1992. $365 p$

CAVAlCANTE, P. B. Frutas comestíveis da Amazônia. 5. ed. 
Belém: Edições CEJUP, CNPq: Museu Paraense Emílio Goeldi, 1991.279p.

CORNER, E.J.H. The seeds of dicotyledons. Cambridge: University Press, 1976. v.1, p. 3-25.

DAMIÃO-FILHO, C. F. Morfologia e anatomia de sementes. Jaboticabal:FCAV/UNESP, 1993. 145p. (Apostila).

DUKE, J.A. Keys for the identification of seedlings of some proeminent wood species in eight forest types in Puerto Rico. Annals of Missouri Botanical Gardens, St. Louis. v.5, n.3, p.314$350,1965$.

ENOCH, I.C. Morphology of germination. In: CHIN, H.F.; ROBERTS, E.H. Recalcitrant crop seeds. Kuala Lumpur: Tropical Press, 1980. p. 6-52.

MOURÃO, K.S.M.; BELTRATI, C.M. Morfologia dos frutos, sementes e plântulas de Platonia insignis Mart. (Clusiaceae). III germinação e plântulas. Acta Amazônica, Manaus, v. 25 n.1/2, p.47-53. 1995.

OLIVEIRA, E.C. Morfologia de plântulas florestais. In: AGUIAR, I.B.; PIÑA-RODRIGUES, F.C.M.; FIGLIOLIA, M.B. (Coord.), Sementes florestais tropicais. Brasília: ABRATES, 1993. p.175214.

VAN DEN BERG, M.E. Revisão das espécies brasileiras do gênero Rheedia L. (Guttiferae). Acta Amazônica, Manaus. v.9, n.1, p.4374. 1979.

VILLAGÓMEZ ROJAS, A. Estudio preliminar de la densidad morfologica distribuicion, producion y comercializacion del achachairu (Rheedia spp.) en Santa Cruz de la Sierra. Santa Cruz de la Sierra: Universidad Autonoma "Gabriel Rene Moreno", Faculdade de Ciencias Agrícolas, 1990. p.32-37. 